\title{
System evaluation of offshore platforms with gas liquefaction processes
}

\author{
Nguyen, Tuong-Van; de Oliveira Júnior, Silvio
}

Published in:

Energy

Link to article, DOI:

10.1016/j.energy.2017.12.043

Publication date:

2018

Document Version

Peer reviewed version

Link back to DTU Orbit

Citation (APA):

Nguyen, T-V., \& de Oliveira Júnior, S. (2018). System evaluation of offshore platforms with gas liquefaction processes. Energy, 144, 594-606. https://doi.org/10.1016/j.energy.2017.12.043

\section{General rights}

Copyright and moral rights for the publications made accessible in the public portal are retained by the authors and/or other copyright owners and it is a condition of accessing publications that users recognise and abide by the legal requirements associated with these rights.

- Users may download and print one copy of any publication from the public portal for the purpose of private study or research.

- You may not further distribute the material or use it for any profit-making activity or commercial gain

- You may freely distribute the URL identifying the publication in the public portal

If you believe that this document breaches copyright please contact us providing details, and we will remove access to the work immediately and investigate your claim. 


\section{Accepted Manuscript}

System evaluation of offshore platforms with gas liquefaction processes

Tuong-Van Nguyen, Silvio de Oliveira Júnior

PII: S0360-5442(17)32076-5

DOI: $\quad$ 10.1016/j.energy.2017.12.043

Reference: EGY 11992

To appear in: Energy

Received Date: 5 April 2017

Revised Date: 5 December 2017

Accepted Date: 10 December 2017

Please cite this article as: Nguyen T-V, de Oliveira Júnior S, System evaluation of offshore platforms with gas liquefaction processes, Energy (2018), doi: 10.1016/j.energy.2017.12.043.

This is a PDF file of an unedited manuscript that has been accepted for publication. As a service to our customers we are providing this early version of the manuscript. The manuscript will undergo copyediting, typesetting, and review of the resulting proof before it is published in its final form. Please note that during the production process errors may be discovered which could affect the content, and all legal disclaimers that apply to the journal pertain. 


\title{
System evaluation of offshore platforms with gas liquefaction processes
}

\author{
Tuong-Van Nguyen ${ }^{\mathrm{a}, *}$, Silvio de Oliveira Júnior \\ ${ }^{a}$ Laboratory of Environmental and Thermal Engineering, Polytechnic School - University of São Paulo, Av. Prof. Luciano \\ Gualberto, 05508-900 São Paulo, Brazil
}

\begin{abstract}
Floating, production, storage and offloading plants are facilities used for offshore processing of hydrocarbons in remote locations. At present, the produced gas is injected back into the reservoir instead of being exported. The implementation of refrigeration processes offshore for liquefying natural gas provides the opportunity to monetize offshore gas resources. The present work analyzes the performance of offshore platforms, from the oil processing to the gas liquefaction system. Different feed compositions, system layouts and liquefaction processes are considered. Potential system improvements are discussed based on an energy and exergy analysis. Compared to a standard platform where gas is directly injected into the reservoir, the total power consumption increases by up to $50 \%$, and the exergy destruction within the processing plant doubles when a liquefaction system is installed. It is therefore essential to conduct a careful analysis of the trade-off between the capital costs and operating revenues for such options.
\end{abstract}

Keywords: Gas liquefaction, Offshore platforms, Thermodynamic analysis, Process integration

\section{Introduction}

Oil and gas platforms are energy-intensive systems requiring mechanical/electrical power, cooling and possibly low-temperature heating. The design and energy demands of these facilities depend on the field conditions (e.g. temperature and pressure), feed properties (e.g. oil, gas, water and carbon dioxide contents), 5 and operating strategies (e.g. gas injection or export) [Bothamley,2004]. However, as pinpointed in Voldsund 6 et al.[2014], operations such as separation, compression, pumping, and power generation are present on all facilities.

Floating production, storage and offloading (FPSO) facilities have gained more and more attention in the

\footnotetext{
*Principal corresponding author. Tel.: +45 4525 4129

Email address: tungu@mek.dtu.dk (Tuong-Van Nguyen)
} 


\begin{tabular}{|c|c|c|c|}
\hline \multicolumn{4}{|c|}{ Nomenclature } \\
\hline$\dot{E}$ & Exergy rate, $\mathrm{W}$ & UT & Utility Plant \\
\hline$\dot{H}$ & Enthalpy rate, $\mathrm{W}$ & \multicolumn{2}{|c|}{ Greek letters } \\
\hline$\dot{Q}$ & Heat rate, $\mathrm{W}$ & $\Delta$ & variation \\
\hline$\dot{W}$ & Power, W & $\varepsilon$ & separation efficiency \\
\hline $\mathrm{T}$ & Temperature, $\mathrm{K}$ or ${ }^{\circ} \mathrm{C}$ & Supe & ipts \\
\hline $\mathrm{p}$ & Pressure, $\mathrm{Pa}$ & * & relative \\
\hline \multicolumn{2}{|c|}{ Abbreviations } & $Q$ & heat transfer \\
\hline $\mathrm{CC}$ & Composite Curves & $W$ & work transfer \\
\hline FPSO & Floating production, storage and offloading & Subs & \\
\hline GCC & Grand Composite Curve & 0 & dead state \\
\hline HRSG & Heat Recovery Steam Generator & cool & cooling \\
\hline LNG & Liquefied Natural Gas & & destruction \\
\hline PP & Processing Plant & feed & feed \\
\hline PR & Peng-Robinson & heat & heating \\
\hline SRK & Soave-Redlich-Kwong & $\min$ & minimum \\
\hline
\end{tabular}

Different studies indicate that installing liquefaction processes on FPSOs is technically feasible, as gas liquefaction processes are well-known systems on offshore applications. Such facilities are named floating liquefied natural gas (FLNG) platforms. Only a few FLNG plants are in operation at present, and the first well-known one is the Prelude plant [International,2009]. Nezamian et al.[2014] pinpoint the complexity of FLNG processing but argue that such systems are already economically viable.

The selection of the gas liquefaction process is of crucial matter. For example, the performance of the liquefaction process is of key importance, but other factors such as the equipment count, dynamic behavior, compactness, safety, etc., are essential [Finn,2002]. For offshore applications, standard mixed-refrigerant systems and expander-based processes are more suitable because of their simplicity of construction and operation, but there is no global consensus on a standard layout. According to Finn[2009], the first choice for a safe liquefaction operation is a double turbo-expander process, because of the non-flammability of nitrogen and the high performance that can be achieved.

Cao et al.[2006] evaluate two types of small-scale liquefaction processes and conclude that the expanderbased system is more efficient than a single mixed-refrigerant process without precooling. Remeljej and 
Hoadley[2006] analyze four liquefaction configurations and claim that processes with mixture are the most efficient ones. Chang[2015] assess the maximum exergy efficiency for several types of gas liquefaction systems and demonstrate, for their particular application, that reverse Brayton cycles can achieve higher efficiencies than basic mixed-refrigerant processes. These studies do not discuss the integration of such systems with the petroleum processing plant, and how the performance of the hybrid LNG-FPSO system can be improved.

Several analyses of primary petroleum processing plants, which do not include gas liquefaction processes, were conducted in the last years. Oliveira Jr. and Van Hombeeck[1997] and Sánchez et al.[2015] conduct exergy analyses of Brazilian oil platforms, including FPSOs, whilst Voldsund et al.[2013,2014] and Nguyen et al.[2014b,2013] assess the performance of Norwegian oil platforms. They show that (i) most exergy destroyed on an offshore plant is destroyed in the power plant (gas turbines) but is mostly unavoidable, and that (ii) the gas treatment process and compression is usually responsible for most of the thermodynamic irreversibility taking place in the processing plant, together with the petroleum heating. These works present valuable findings, but none actually investigates the integration of LNG processes and the performance of the resulting hybrid system.

To the knowledge of the authors, there is no work in the scientific literature that gives an overview of the energy and exergy demands of hybrid FLNG systems. Consequently, none actually discusses the impact of different system configurations on the performance of offshore platforms with gas liquefaction processes. The main purpose of this work is to address these gaps by developing models that represent various alternatives for the offshore production of liquefied natural gas, considering different system layouts and feed compositions. Several promising configurations are identified and analyzed, and possibilities for improvements are discussed.

\section{Methods}

\subsection{System description and simulation}

As emphasized by Bothamley[2004] and by Voldsund et al.[2014], an offshore platform can be divided into two sections: a processing plant and a power plant. The main functions of the processing plant are to process the petroleum feed from the different wells (Figure 1), separate the oil, gas and water phases, and purify them in dedicated sections. This plant consists of the following processes: the production manifold and separation, oil pumping and treatment, produced water treatment, vapor recovery unit, gas compression, gas treatment, gas injection or export and water injection. The power and heat required on-site are produced in the power plant by burning a fraction of the associated gas in gas turbines, and transferring heat through a heat recovery system. The following sub-sections give an overview of the processes present on-site, together with the values of the set temperatures and pressures used for the simulations. 


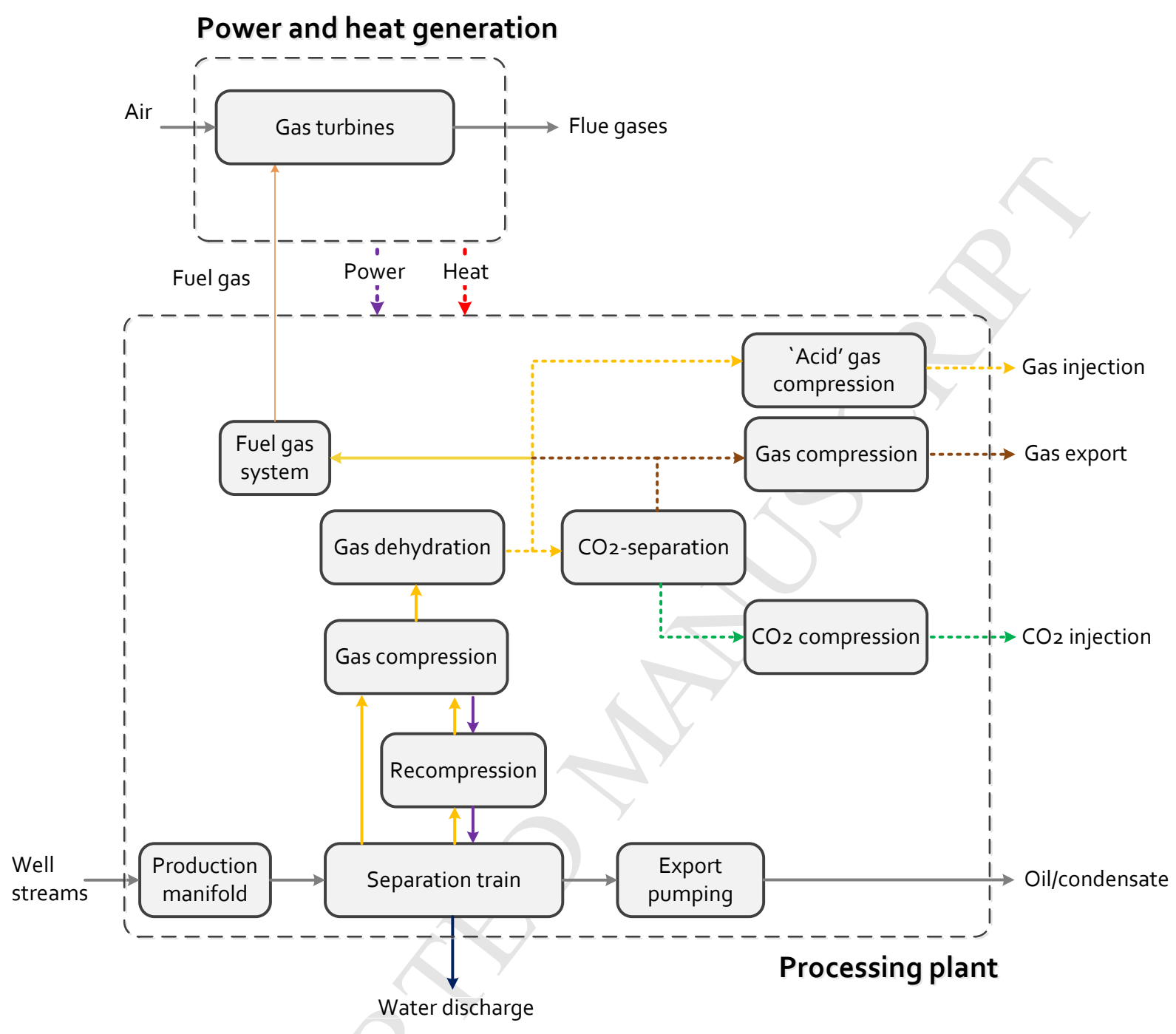

Figure 1: System overview of the processes present on an FPSO

Different thermodynamic models were used to compute the physical (e.g. liquid-vapor equilibrium) and chemical transformations (e.g. amine absorption), and to calculate the energy (e.g. power) requirements. The system simulations were carried out with Aspen Plus version 7.2 [Aspen Technology,1999]. Three petroleum compositions (Table 1) are considered in this work, they are three samples of feeds encountered in FPSO operations. The two first compositions are characterized by a moderate and high content of carbon dioxide, and acid gas treatment is required. The last one is a volatile oil without a high fraction of butanes, so separate condensate treatment is not necessary. The heavy fraction $\left(\mathrm{C}_{5}^{+}\right)$is simulated as a blend of alkanes with a carbon number between 5 and 20, based on the data provided by the operators. It is adjusted to match the specific gravity measurements. Standard efficiencies were assumed for the process simulations 
68

(Table 2), based on data provided by the platform operators involved in the project. A sensitivity analysis on these parameters is out of scope of this work, but such findings are presented in Nguyen et al.[2013] and in Voldsund et al.[2014].

Table 1: Petroleum compositions, with fractions given on a molar basis

\begin{tabular}{lrrr}
\hline & Feed 1 & Feed 2 & Feed 3 \\
\hline $\mathrm{CO}_{2}$ & 6.9 & 26.1 & 0.00 \\
$\mathrm{~N}_{2}$ & 0.6 & 0.3 & 0.4 \\
$\mathrm{C}_{1}$ & 50.3 & 41.1 & 63.1 \\
$\mathrm{C}_{2}$ & 6.1 & 4.7 & 7.5 \\
$\mathrm{C}_{3}$ & 4.6 & 2.8 & 5.2 \\
$\mathrm{C}_{4}$ & 2.5 & 1.7 & 1.0 \\
$\mathrm{C}_{5}^{+}$ & 29.0 & 23.3 & 21.0 \\
\hline
\end{tabular}

The hydrocarbon processing system (separation, vapor recovery unit, gas compression, oil stabilisation) is simulated using the Peng-Robinson equation of state [Peng and Robinson,1976], which is the most common model used in the offshore oil and gas industry (Table 3). The one of Redlich-Kwong [Redlich and Kwong,1949] with Soave modifications [Soave,1972] may be used as well as it deems satisfactory results. The main problem with the Peng-Robinson equation of state is the prediction of the liquid volume and density for $\mathrm{CO}_{2}$-rich fluids.A crude production of about 150,000 barrels per day was assumed, as suggested from the industrial project partners, as it corresponds to the production of a standard offshore platform, and this is equivalent to a feed flow of about $200 \frac{\mathrm{kg}}{\mathrm{s}}$.

Table 2: Component parameters of the offshore oil and gas processing

\begin{tabular}{ll}
\hline Parameter & Value \\
\hline Heat losses & - \\
Pressure drops & - \\
Oil cooler temperatures & $60^{\circ} \mathrm{C}$ \\
Gas cooler temperatures & $40{ }^{\circ} \mathrm{C}$ \\
Compressor efficiency & $75 \%$ \\
Generator efficiency & $96 \%$ \\
\hline
\end{tabular}




\subsubsection{Processing plant}

Petroleum conditioning. The reservoir fluids from the producing wells enter one or several production manifolds, where all streams are mixed and their pressure is reduced to about $1500 \mathrm{kPa}$. They then enter the separation section, in which oil, gas and water are separated in several stages operated at different temperature and pressure levels. The pressure is decreased at the inlet of each separator and the temperature may be increased to enhance the separation between the water and hydrocarbon phases. The separated oil is treated in a dedicated oil treatment and pumping section, where the water and salt contents are decreased to satisfy the crude export requirements. The produced water is discharged into the sea or in a dedicated reservoir after removal of the oil droplets.

Table 3: Operating conditions of the feed processing

\begin{tabular}{lll}
\hline Process & Parameter & Value \\
\hline Separation & Pressure & $\geq 1.5 \mathrm{bar}$ \\
& & $\leq 15 \mathrm{bar}$ \\
& Temperature & $85^{\circ} \mathrm{C}$ \\
Oil export & Reid Vapor & $0.7 \mathrm{bar}$ \\
& Pressure $\left(38^{\circ} \mathrm{C}\right)$ & \\
Vapor recovery unit & Pressures & $\geq 1.5 \mathrm{bar}$ \\
& & $\leq 15 \mathrm{bar}$ \\
Gas compression & Pressures & $\geq 15 \mathrm{bar}$ \\
& & $\leq 55 \mathrm{bar}$ \\
\hline
\end{tabular}

As a basis for the simulations, the reservoir fluid enters at $20^{\circ} \mathrm{C}$ and $1500 \mathrm{kPa}$, in a three-phase equilibrium - gas, oil and water phases (vapor and two non-miscible liquids). These feed conditions correspond to real-time data and to assumptions presented in the literature [Oliveira Jr. and Van Hombeeck,1997]. This physical equilibrium is adjusted in the separation process by controlling the operating temperatures and pressures, by throttling valves and heaters, using a heating oil that recovers heat from the utilities. The separation and recompression systems consist of three stages each, and the final separation pressure is constrained by the allowable vapor pressure when exporting the crude oil. The aim is to recover the $\mathrm{C}_{5}^{+}$ hydrocarbons in the oil, the $\mathrm{C}_{1}-\mathrm{C}_{3}$ range in the gas and the $\mathrm{C}_{4}$ in either liquid or gas form, depending on the platform operators.

Gas compression and dehydration. The gas recovered from the second and third separation stages is first compressed in a vapor recovery unit to the initial feed pressure. The number of recompression stages is equal or higher to the number of separation levels. The recompressed gas is then mixed with the gas recovered at the first stage and compressed further to $5500 \mathrm{kPa}$ for treatment purposes. Natural gas dehydration is a 
widely-used treatment process implemented to remove most of the water vapor to avoid hydrate formation and possible freezing, especially if the gas is exported through pipelines. Molecular sieves may be used for drying the natural gas, and this option is currently considered in the Brazilian petroleum industry. These micro-porous materials can selectively adsorb gases such as water and are then regenerated by purging with a hot gas flow or by electric heating at temperatures between 200 and $300{ }^{\circ} \mathrm{C}$. All these systems have the capability of removing enough water to complain with the purity requirements of the gas export and liquefaction processes. The operating pressure is set to $5500 \mathrm{kPa}$.

$\mathrm{CO}_{2}$-treatment. The next process operations are specific to FPSOs operating in pre-salt oil fields. For example, for most Norwegian fields, gas is further compressed for export to the shore, or injected into the reservoir. In the present case, the recovered gas may have high content of carbon dioxide, up to $60 \%$. High contents of carbon dioxide are not desired, because those would result in pipeline corrosion if the gas is exported as a liquid, or in heat exchanger plugging if the gas is first liquefied. The most common technologies for $\mathrm{CO}_{2}$-separation, available commercially, are chemical absorption with amines, physical absorption with methanol or glycols, membranes and cryogenic separation. The selection of one process rather than another depends on the acid gas properties (temperature, pressure, $\mathrm{CO}_{2}$-fraction), system scale (gas flowrate to treat), product requirements (desired $\mathrm{CO}_{2}$-content), economics and offshore applicability.

Chemical absorption systems are the most mature processes and the $\mathrm{CO}_{2}$-concentrations can be decreased to the $50 \mathrm{ppmv}$ range. The chemical absorption system is represented by a black-box for which the heating and cooling demands are assumed to be 3.7 and $4.1 \mathrm{MJ}$ per $\mathrm{kg}$ of recovered $\mathrm{CO}_{2}$, based on the figures presented in Tock and Maréchal[2013].

Membrane systems are more compact but cannot be used for achieving degrees of separation as high as chemical absorption ones. The $\mathrm{CO}_{2}$-content can be decreased down to $3 \%$ in volume, which is satisfying if the gas should be exported, but not sufficient for gas liquefaction purposes. Membrane systems are preferred for Brazilian pre-sal fields, considering a difference of 55 to 3 bar between the feed and the retentate. Membrane systems are modeled here as a single-module membrane using the approach of Pettersen and Lien[1994] and applied in Gassner et al.[2009]. They are represented by a black-box for which the input is the feed composition and the output the final water content. The output values are set based on measurements provided by the operators.

The present work does not consider purification operations from nitrogen, oxygen, sulphur and mercury, which are operations less likely than water and carbon dioxide separation. The recovered gas from the vapor recovery unit is then compressed to the pressure of the gas treatment system. Different processing pathways are then possible (Table 4), depending on the feed composition and operating strategies of the platform:

- if the gas has a negligible $\mathrm{CO}_{2}$-content, only dehydration by molecular sieves is required and no $\mathrm{CO}_{2}$ treatment system is installed on the facility, whether the gas is ultimately exported or injected; 
- if the $\mathrm{CO}_{2}$ content exceeds $3 \%$ and the natural gas is exported through pipelines, the acid gas undergoes first dehydration and then membrane processing;

- if the $\mathrm{CO}_{2}$ content exceeds $3 \%$ and the natural gas is liquefied for further export, the acid gas goes first through a combined membrane and amine system to achieve a $\mathrm{CO}_{2}$-concentration of $50 \mathrm{ppmv}$, and is then dehydrated by molecular sieves;

- if the acid gas is injected, neither a membrane nor an amine system is required, and the injection pressure depends solely on the gas flow rate and $\mathrm{CO}_{2}$-concentration;

- if natural gas and carbon dioxide should be injected in separated wells, only a membrane system is required, as a $\mathrm{CO}_{2}$-concentration of $3 \%$ is acceptable.

In the third case, the combined membrane and amine system may be replaced by a larger-scale amine process, which may be simpler and easier to control, at the expense of greater economic costs and space requirements [Kayat et al.,2012;Shane et al.,2015]. The membrane and chemical absorption system sizes may also be optimized with respect to their energy use or economic costs, but this is out of scope of the present study.

Table 4: Specifications of the gas treatment technologies

\begin{tabular}{lll}
\hline Process & Parameter & Value \\
\hline Dew point control & Pressure & $\geq 50 \mathrm{bar}$ \\
Membranes & $\mathrm{CO}_{2}$-fraction & $3 \%$ \\
& Selectivity $\mathrm{CO}_{2} / \mathrm{CH}_{4}$ & 21 \\
& Permeability & $9 \mathrm{barrer}$ \\
& Permeate pressure & $3 \mathrm{bar}$ \\
& CO -fraction & $50 \mathrm{ppm}$ \\
& Stripper pressure & $2 \mathrm{bar}$ \\
& Reboiler temperature & $117^{\circ} \mathrm{C}$ \\
\hline
\end{tabular}

Gas export, injection and liquefaction. The choice of purifying, injecting or exporting gas depends on the initial petroleum composition. According to FPSO operators, it is preferable to export gas in the first stage of a field lifetime, when the ratio oil - gas to water is at its maximum, and the hydrocarbon production is near its peak. In the declining phase, when the crude oil contains about $50 \%$ of water, part of the gas may still be treated and exported, while the remaining fraction is directly injected. Finally, in end-life conditions, when the water and carbon dioxide contents represent more than $80-90 \%$ of the total feed content, the acid gas is directly injected, and clean gas is imported from other facilities to fuel the gas turbines. Three modes 
of operation are identified: (i) Mode A: all the produced gas is injected - no $\mathrm{CO}_{2}$-treatment is required; (ii) Mode B: natural gas is exported while carbon dioxide is injected - $\mathrm{CO}_{2}$-treatment is necessary and the $\mathrm{CO}_{2}$ content should not exceed 3\%; (iii) Mode C: natural gas and carbon dioxide are injected in separate wells - $\mathrm{CO}_{2}$-treatment is necessary. Natural gas may be liquefied and cooled to $-162{ }^{\circ} \mathrm{C}$ at pressures as high as 50 bar. Carbon dioxide and water should be removed upstream to prevent freezing issues, to concentrations as low as 50 and 10 ppmv. Part of the produced gas is used for power and heating generation purposes, while the remaining gas is either exported or injected (Table 5). Natural gas may be injected along with carbon dioxide. The injection pressure can be as high as 550 bar and is a function of the flowrate and $\mathrm{CO}_{2}$-concentration.

Table 5: Specifications of the final gas processing operations

\begin{tabular}{lll}
\hline Process & Parameter & Value \\
\hline Gas lift & Pressure & $\leq 250 \mathrm{bar}$ \\
Gas injection & Acid gas pressure & $\leq 450 \mathrm{bar}$ \\
& Clean gas pressure & $\leq 550 \mathrm{bar}$ \\
Gas export & Pressure & $\leq 245 \mathrm{bar}$ \\
Gas liquefaction & Gas pressure & $45 \mathrm{bar}$ \\
& Gas temperature & $-162{ }^{\circ} \mathrm{C}$ \\
Mixed-refrigerant & Working fluid & $\mathrm{CH}_{4}, \mathrm{C}_{2} \mathrm{H}_{6}$ \\
& & $\mathrm{C}_{3} \mathrm{H}_{8}, \mathrm{~N}_{2}$ \\
& Maximum pressure & $\leq 30 \mathrm{bar}$ \\
& Minimum pressure & $\geq 1.013 \mathrm{bar}$ \\
& Working fluid & $\mathrm{N}_{2}$ \\
& Maximum pressure & $\leq 90 \mathrm{bar}$ \\
& Minimum pressure & $\geq 1.013 \mathrm{bar}$ \\
\hline
\end{tabular}

\subsubsection{Utilities}

The utilities consist of a power and heat generation block, which includes one or several gas turbines combined with a waste heat recovery process, and a cooling system, which is a heat exchanger network where seawater is pumped on-site. Direct heating from the turbine exhausts is generally not recommended and a heating fluid such as high-pressure liquid glycol or water is used to transfer heat from one process to another. Three utility systems are simulated (Table 6) - the power and heat generation system is represented by gas turbines operating in parallel, and a waste heat recovery system. The component efficiencies, air-to-fuel and pressure ratios were adapted to reproduce the characteristics of the LM2500+ model of General Electric [McCarrick and Kenneth,2012]. This is an aeroderivative gas turbine common for offshore applications 
with an ISO base rating of $31.9 \mathrm{MW}$, a gross efficiency of $38.8 \%$ (LHV) and an exhaust temperature of $525^{\circ} \mathrm{C}$. The heat recovery system consists of an indirect heating loop working with hot water, while the cooling system is a direct cooling loop with seawater.

Table 6: Design parameters of the utility system

\begin{tabular}{lll}
\hline Process & Parameter & Value \\
\hline Cooling system & Working fluid & Seawater \\
& Inlet temperature & $25^{\circ} \mathrm{C}$ \\
& Discharge temperature & $45^{\circ} \mathrm{C}$ \\
Gas turbine & Pressure ratio & $23: 1$ \\
& Compressor efficiency & $85 \%$ \\
& Turbine efficiency & $90 \%$ \\
& Air-to-fuel ratio & 45 \\
Waste heat recovery & Exit temperature & $120{ }^{\circ} \mathrm{C}$ \\
\hline
\end{tabular}

The cryogenic temperatures required in gas liquefaction create the need for specific refrigeration processes. They can be divided into three sub-categories depending on the system layout and on the type of refrigerant [Mokhatab and Poe,2012]: the cascade, mixed-refrigerant and expansion-based systems [Barclay and Denton,2005].

Mixed-refrigerant systems use, as their name suggests, mixtures of refrigerants (generally methane, ethane, ethylene, propane, butanes, pentanes and nitrogen) as working fluids. The refrigeration effect is produced by the Joule-Thomson expansion (i.e. adiabatic expansion through a valve). All the mixedrefrigerant cycles are characterized by the following advantages. First, a better heat transfer can be expected in the heat exchangers, as the latent heat of vaporization of the refrigerant(s) is used to cool and condense the natural gas. Secondly, the mixture composition can be tuned to the feed composition to obtain a better match of the temperature - heat profiles. The most popular and efficient process for onshore applications is the propane pre-cooled mixed-refrigerant process (C3MR), which is not suitable for offshore applications because of its high complexity. The dual mixed refrigerant process (Figure 2), which consists of two refrigeration cycles using different working fluids, is a promising alternative for offshore implementations, and was installed on the Prelude FPSO.

Expander processes are based on the use of a reverse Brayton cycle, and the refrigeration effect is generated by vapor expansion through a turbo-expander from which power is extracted. The simplest configuration is the single reverse Brayton process, but the dual expander system (Figure 3), using nitrogen as working fluid, has also been proposed in several articles on FLNG.

The dual mixed-refrigerant (Figure 2) and dual-expander (Figure 3) systems are investigated further in 


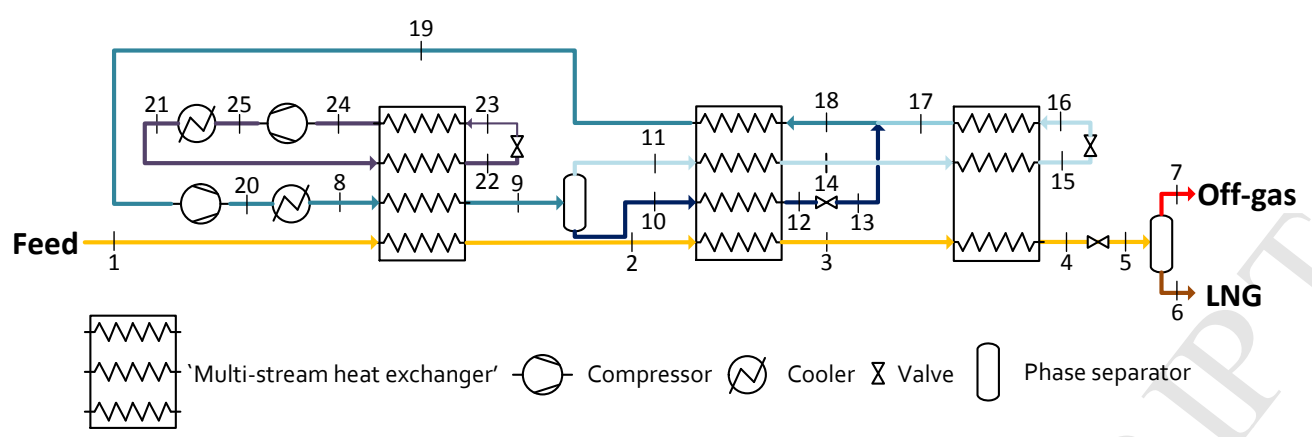

Figure 2: Process flowsheet of the dual mixed-refrigerant process
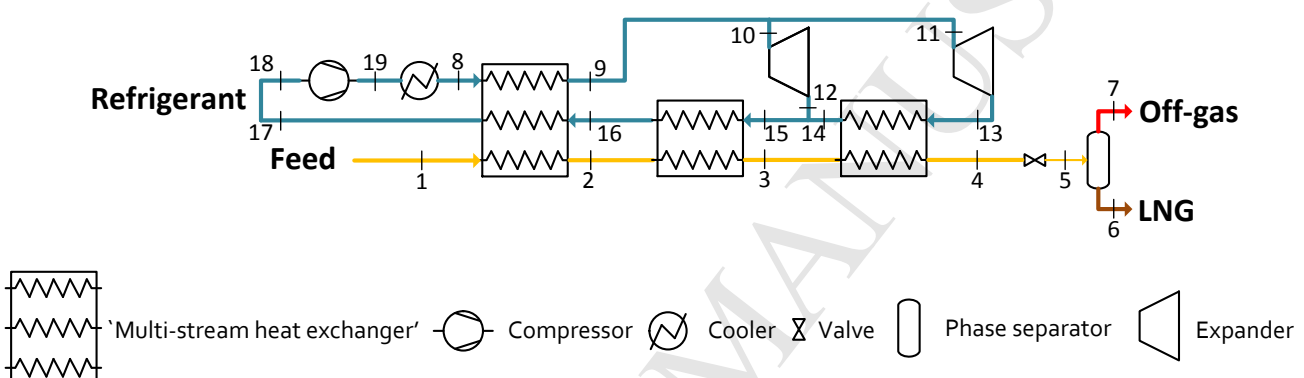

Figure 3: Process flowsheet of the dual expander process

this work.

\subsection{System evaluation}

\subsubsection{Energy analysis}

Energy can be stored, transformed from one form to another and transferred between systems, but can neither be created nor destroyed (conservation law). The purpose of the energy integration method is to minimize the demands for external heating and cooling, by maximizing the heat recovery within a given system, and by optimising its operating conditions. The reader is referred to Kemp[2006] for a detailed description of the pinch analysis method, which is a systematic approach to such problems. The first step is to identify the hot and cold streams, with their corresponding temperatures and enthalpies.

Minimum individual temperature differences $\left(\Delta T_{\min } / 2\right)$ of 2,4 and $8 \mathrm{~K}$ [Nguyen et al.,2014c] are assumed for phase-changing, liquid and gaseous streams. The potential for internal heat recovery can be investigated, and minimizing the external cooling and heating demands results in smaller fuel demand and greater gas production. 


\subsubsection{Exergy analysis}

Exergy may be defined as the 'maximum theoretical useful work (shaft work or electrical work) as the system is brought into complete thermodynamic equilibrium with the thermodynamic environment while the system interacts with it only' [Moran,1989]. Unlike energy, exergy is not conserved but some is destroyed because of the irreversible phenomena taking place in real processes (e.g. chemical reactions, heat transfer). The exergy balance for the processing plant of the oil and gas facility can be expressed as:

$$
\dot{E}_{\text {feed }}+\dot{E}_{\text {heat }}^{Q}+\dot{E}_{\mathrm{UT}}^{W}=\sum_{k} \dot{E}_{k}+\dot{E}_{\mathrm{cool}}^{Q}+\dot{E}_{d, \mathrm{PP}}
$$

The left-hand side term represents, on a time rate basis, the exergy associated with the feed entering the processing plant (i.e. reservoir fluid) $\dot{E}_{\text {feed }}$ and the exergy transfers with the heating medium $\dot{E}_{\text {heat }}^{Q}$ and power $\dot{E}_{\mathrm{UT}}^{W}$ from the utility plant that are consumed within the separation and treatment modules. The right-hand side term denotes the exergy of the outlet streams of the processing plant (i.e. oil, gas, condensate, flared gas, fuel gas, produced water) $\sum_{k} \dot{E}_{k}$ and the exergy gain discarded with the cooling medium discharged to the environment $\dot{E}_{\text {cool }}^{Q} . \dot{E}_{d, \mathrm{PP}}$ is the exergy destroyed in the processing plant. The dead state is taken to be $25^{\circ} \mathrm{C}$ and 1 atmosphere and the reference environment of Szargut[1989] is selected for the chemical exergy calculations. Data on the reservoir fluid initial pressure, at the inlet of the production manifold, was not available, and this process is therefore excluded from the analysis.

\subsection{System performance}

The system performance depends on the efficiency of each physical and chemical transformation required to separate and purify water, oil and gas. The separation quality depends on the temperatures and pressures of each two- and three-phase separator, which is correlated to the site heating, cooling and power demands, and thus to the system energy and exergy use. The following indicators are defined to assess the efficiency of each process and the overall system performance:

- the recovery of light hydrocarbons $\varepsilon_{\text {light }}$, which is defined as the ratio of the light hydrocarbons $\left(\mathrm{C}_{1}\right.$ to $\mathrm{C}_{4}$ ) present in the recovered gas to those in the feed;

$$
\varepsilon_{\text {light }}=\sum_{i=1}^{4} \frac{\dot{n}_{C_{i}, \text { gas }}}{\dot{n}_{C_{i}, \text { feed }}}
$$

- the recovery of heavy hydrocarbons $\varepsilon_{\text {heavy }}$, which is defined as the ratio of the heavy hydrocarbons $\left(\mathrm{C}_{5}^{+}\right)$present in the produced crude to those in the feed;

$$
\varepsilon_{\text {heavy }}=\sum_{i=5}^{n} \frac{\dot{n}_{C_{i}, \text { oil }}}{\dot{n}_{C_{i}, \text { feed }}}
$$


- the separation efficiency $\varepsilon_{\text {sep }}$, defined as the product of the two latter parameters;

$$
\varepsilon_{\text {sep }}=\varepsilon_{\text {light }} \cdot \varepsilon_{\text {heavy }}
$$

- the specific power consumption per unit of exported oil and gas $w$, if relevant;

- the exergy destruction ratio $y_{\mathrm{d}, k}^{*}$, defined as the exergy destruction taking place in the $k$-th component or process, over the exergy destruction of the entire system.

$$
y_{\mathrm{d}, k}^{*}=\frac{\dot{E}_{\mathrm{d}, k}}{\dot{E}_{\mathrm{d}, \mathrm{system}}}
$$

\section{Results}

\subsection{Oil and gas processing}

The system performance is analyzed at first without considering the integration of the gas liquefaction process (Table 7), assuming that all the produced gas is injected, as two streams of natural gas and carbon dioxide. This corresponds to a scenario in which the FPSO does not present any gas export infrastructure, which is the most plausible scenario.

Table 7: Material flows within the processing plant of the offshore plant, expressed as a percentage of the feedstock input on a weight basis

\begin{tabular}{cccccc}
\hline & Feed & Crude oil & Natural gas & Fuel gas & $\mathrm{CO}_{2}$ \\
\hline Composition 1 & $100.0 \%$ & $83.5 \%$ & $12.1 \%$ & $0.7 \%$ & $3.8 \%$ \\
Composition 2 & $100.0 \%$ & $74.6 \%$ & $9.3 \%$ & $0.9 \%$ & $15.1 \%$ \\
Composition 3 & $100.0 \%$ & $78.1 \%$ & $21.4 \%$ & $0.5 \%$ & $0.0 \%$ \\
\hline
\end{tabular}

The separation performance (Table 8) depends on the system operating conditions and feed composition, and no general trend can be drawn based solely on the $\mathrm{CO}_{2}$-content. The results suggest that higher recovery of the light hydrocarbons and lower recovery of the heavy ones are achieved for volatile feeds, since more medium-weight hydrocarbons are entrained with the gas flows.

\subsubsection{Energy demands}

On an offshore platform, the well-streams are separated into the flows of crude oil, natural gas, fuel gas, and, if relevant, carbon dioxide for injection. The energy content of hydrocarbons is dominated at more than $97 \%$ by their chemical energy, which can be as high as $50 \frac{\mathrm{MJ}}{\mathrm{kg}}$ on a higher heating value basis, and amounts to 5560, 4960 and $6230 \mathrm{MW}$ for the cases with a low, high and negligible content of carbon dioxide. Up to 
Table 8: Separation performance for each feed composition

\begin{tabular}{lccc}
\hline & $\varepsilon_{\text {light }}$ & $\varepsilon_{\text {heavy }}$ & $\varepsilon_{\text {sep }}$ \\
\hline Composition 1 & $93.5 \%$ & $99.0 \%$ & $92.5 \%$ \\
Composition 2 & $96.0 \%$ & $98.8 \%$ & $94.8 \%$ \\
Composition 3 & $96.0 \%$ & $97.9 \%$ & $94.0 \%$ \\
\hline
\end{tabular}

$3 \%$ of the feed chemical energy (Table 9) is actually transformed into power and heat in the cogeneration plant. Less than $5 \%$ is lost with the carbon dioxide injected into the reservoir, as part of the natural gas flows through the $\mathrm{CO}_{2}$ membrane into the permeate stream.

Table 9: Energy flows within the processing plant of the offshore plant, expressed as a percentage of the feedstock input on a higher heating value basis

\begin{tabular}{lccccc}
\hline & Feed & Crude oil & Natural gas & Fuel gas & $\mathrm{CO}_{2}$ \\
\hline Composition 1 & $100.0 \%$ & $74.4 \%$ & $23.0 \%$ & $1.4 \%$ & $1.2 \%$ \\
Composition 2 & $100.0 \%$ & $74.4 \%$ & $20.0 \%$ & $2.0 \%$ & $3.6 \%$ \\
Composition 3 & $100.0 \%$ & $62.4 \%$ & $36.7 \%$ & $0.9 \%$ & $0.0 \%$ \\
\hline
\end{tabular}

The total power consumption varies significantly from one facility to another. It amounts to a minimum of $60 \frac{\mathrm{kJ}}{\mathrm{kg}_{\text {feed }}}$ if the petroleum does not contain any $\mathrm{CO}_{2}$ and natural gas is exported, and to a maximum of $180 \frac{\mathrm{kJ}}{\mathrm{kg}_{\text {feed }}}$ if the feed has a high $\mathrm{CO}_{2}$ content and natural gas is injected. The power consumption is shared between: (i) the separation process, for the water and oil recirculation; (ii) the vapor recovery unit; (iii) the associated gas compression (1st stage, before treatment, and further stages, after dehydration and removal). In all cases, the gas compression steps are the major power consumers, while the power required in the separation step is negligible. The export and injection modes present minor differences in power and cooling demands, since the only change is the final gas pressure after all the treatment operations.

Heating takes place in two processes (Figure 4): the separation unit, to preheat the crude at the inlet of the separation stages, and to a minor extent, in the fuel gas system, to preheat the fuel before combustion in the gas turbine. Cooling is required for removing medium-weight hydrocarbons as liquid droplets in the scrubbers in the gas compression operations, and the cooling demand is greater than the heating use. All the processing plants under study feature a pinch point at the highest system temperature. In other words, it implies that a well-integrated system does not have any need for external heating, which opens possibilities for waste heat recovery from the turbine exhausts.

For the case with the lowest $\mathrm{CO}_{2}$-content, the demand of the $\mathrm{CO}_{2}$-compression process is negligible, the gas compression and export systems being the major power consumer. The opposite trend is found for the 
case with the highest $\mathrm{CO}_{2}$-content. Significant quantities of methane are slipped with carbon dioxide at a low permeate pressure after the membrane unit, and this leads to an exponential increase of the power consumption of the $\mathrm{CO}_{2}$-compression system.

\subsubsection{Exergy accounting}

The exergy destroyed on-site represents less than $3 \%$ of the total exergy entering with the inflowing streams. The feed exergy consists mainly of the chemical exergy of the hydrocarbons, which represents up to $98 \%$ (Figure 5). Their physical exergy is negligible in comparison, since petroleum enters the platform at a temperature close to the atmospheric conditions. Most exergy is actually transiting through the platform with the oil and gas material streams without being transformed, but just separated, which may at first give the impression of a high system efficiency.

Most exergy destruction on the platform corresponds to the power generation system, because of the inherent irreversibilities associated with the combustion process. However, these inefficiencies are unavoidable - they can be reduced only marginally with adjustments of the combustion temperature and air-to-fuel ratio. The irreversibilities taking place in the heating and cooling systems (waste heat recovery and seawater cooling) are allocated to the relevant sub-system in the processing plant.

Focusing on the processing plant, it can be seen that the most exergy-destroying process is the $\mathrm{CO}_{2}$ compression and injection process, if the feed has a high $\mathrm{CO}_{2}$-content, and the gas injection system if the feed has a low $\mathrm{CO}_{2}$-content (Figure 6). The gas compression and oil stabilization systems also represent a significant share of the total exergy destruction in all cases, because of the large compression ratio and the high heating demand.

A more thorough investigation of the entire platform, splitting the exergy destruction share per type of component, shows as well that the combustion process is responsible for most irreversibilities on-site. It is followed by the compressors, turbines, coolers and heaters, which suggests that efforts should focus on improving the performance of the turbomachinery, especially of the gas processing trains. It is also possible to focus on a better use of the waste heat from the exhaust gases or from the produced gas to cool. The first option is more feasible in practice because of the higher exhaust temperature, in the range of 500 to $550{ }^{\circ} \mathrm{C}$, while the second one is made challenging with a more modest $120^{\circ} \mathrm{C}$.

\subsection{Gas liquefaction}

\subsubsection{Energy mapping}

A comparison of the processes under study shows that, as suggested in the literature, mixed-refrigerant processes have smaller net power consumption and are therefore more efficient. The specific power consumption per unit of liquefied gas is in the range of $800-900 \frac{\mathrm{kJ}}{\mathrm{kg}_{\mathrm{LNG}}}$ for the dual mixed-refrigerant case. Higher figures are found for the expansion-based systems, of $1100-1200 \frac{\mathrm{kJ}}{\mathrm{kg}_{\mathrm{LNG}}}$ for the dual set-up. These numbers 
can be compared against the energy content of the produced LNG, which is $53.4 \frac{\mathrm{MJ}}{\mathrm{kg}_{\mathrm{LNG}}}$ (higher heating value) or $48.4 \frac{\mathrm{MJ}}{\mathrm{kg}_{\mathrm{LNG}}}$ (lower heating value) at $15^{\circ} \mathrm{C}$ and 1.013 bar. The previous figures are thus equivalent to a power consumption of 0.22 and $0.30 \frac{\mathrm{kWh}}{\mathrm{kg}_{\mathrm{LNG}}}$, and to $1.7 \%$ and $2.2 \%$ of the LNG energy content (LHV basis). The cooling demand is the highest for the mixed-refrigerant processes, because of the high heat transfer in the cryogenic heat exchangers.

A comparison of the temperature-heat profiles (Figure 7) illustrates significant differences in the heat transfer process in the cryogenic heat exchangers. As expected, the temperature-heat profile of the mixed refrigerants follows closely the temperature-heat profile of the natural gas mixture because of the phase changes on both sides, while large temperature differences are found in the case of expansion-based systems. These findings are confirmed by the values of the conductance of the cryogenic heat exchangers (UA). When normalised for $1 \mathrm{~kg}$ of LNG, the thermal conductance is approximately $210 \frac{\mathrm{kW}}{\mathrm{K}}$ (dual reverse Brayton) and $410 \frac{\mathrm{kW}}{\mathrm{K}}$ (dual mixed refrigerant).

\subsubsection{Exergy mapping}

The DMR process displays the smallest exergy destruction of the two processes, as a result of the better temperature-enthalpy profile matching in the cryogenic heat exchangers. The heat transfer process in the cryogenic heat exchangers is responsible for about $30 \%$ to $55 \%$ of the total exergy destruction in the mixedrefrigerant processes, as a result of the significant amount of heat transferred (more than $2800 \frac{\mathrm{kJ}}{\mathrm{kg}_{\mathrm{LNG}}}$ ). Most exergy is destroyed in the turbomachinery components (more than 60\%) in the expander system, because of the large nitrogen flowrate and high pressure ratios.

\subsection{Hybrid system}

\subsubsection{Energy demands}

In all cases, whether the feed petroleum has a high or low content of carbon dioxide, the integration of the liquefaction plant results in a significantly greater power consumption (nearly twice as much as the initial value, without liquefaction) of the processing plant. The benefits of compressing the associated gas to a lower pressure, of only 50 bar instead of 250-550 bar, are largely outweighed by the power demand of the refrigeration cycles.

The power consumption of the separation, oil pumping, produced water, recompression and gas compression sections are not affected, as these sections are upstream and do not interact with the refrigeration plant. However, the fuel gas demand is higher since the gas liquefaction process is more energy-intensive than the gas compression one. These trends are valid for all cases, which suggests that these results can be generalised to all types of FPSOs.

If the feed contains a negligible amount of carbon dioxide, the heating requirement increases marginally because of the greater fuel consumption (Figure 8). In theory, all the heating demand could be covered 
by further process integration, recovering heat from the crude oil in the separation process or from the hot gases after compression.

The total heating demand increases with the $\mathrm{CO}_{2}$-content of the petroleum because of the amine regeneration step. Heat from the turbine exhausts should then be recovered to supply the energy required in the stripper reboiler at $120^{\circ} \mathrm{C}$. It is worth noting that these heating requirements are calculated for a hybrid membrane-absorption system, where the amine is used only to decrease the $\mathrm{CO}_{2}$-content from $3 \%$ to 50 ppmv. A full amine absorption system to decrease the $\mathrm{CO}_{2}$-content would present an even greater heating demand, which would impede possibilities for heat recovery from the off-gases. Otherwise, in all cases, the seawater demand rises significantly because of the excess heat from the refrigeration cycle, from around $25 \mathrm{MW}$ to $35 \mathrm{MW}$.

\subsubsection{Exergy accounting}

The gas liquefaction process is responsible for most exergy destruction within the processing plant (Figure 9 and Figure 10). These findings illustrate the low efficiency of these cryogenic processes (30-45\%) compared to the gas compression systems (50-60\%), and the difficulties of increasing the temperature-based exergy at low temperatures. However, the gas liquefaction process represents only up to $15 \%$ of the exergy destruction within the whole platform, far behind the combustion and power generation steps.

\section{Discussion}

Offshore processing. Several works in the last decade assess the performance of oil and gas processing systems, excluding liquefaction processes. Bothamley[2004] compare the processing schemes in the North Sea and Gulf of Mexico regions, and conclude that the gas compression is the most energy-intensive process. These findings are supported by Svalheim and King[2003], Voldsund et al.[2013,2014] and Nguyen et al.[2014a,b,2013] who focus exclusively on Norwegian facilities processing volatile and heavy oils. They are also confirmed in the further work of Sánchez and de Oliveira Jr.[2015];Sánchez et al.[2015] on Brazilian plants. The system performance can be enhanced (i) by exploiting the waste heat, through e.g. steam Rankine cycles on exhaust gases or organic Rankine cycles on the natural gas, (ii) by further energy integration, which may be challenging in practice, or (iii) by improving the compression operations, through e.g. parallel and smaller trains.

Acid gas treatment. The integration of a gas liquefaction process results in a more complex acid gas treatment scheme, since an amine module may replace or be placed downstream usual membrane systems. Bunnag et al.[2011] argue that a large-scale amine system may be preferable than a hybrid membrane and amine module, but contradictory findings are presented in Kayat et al.[2012] and in Shane et al.[2015]. These works suggest that favoring one option rather than another depends on each site conditions. 
Gas liquefaction. The selection of a mixed-refrigerant or expander-based process on FLNGs is still subject to discussions, and it is difficult to generalize the present results with others, because of the different assumptions on the operating conditions. Remeljej and Hoadley[2006] compare the thermodynamic performance of the SMR process with other expansion systems, which are not presented in the present work. They find that the SMR process is preferable against expansion-based processes, as it presents the smallest specific power requirement. The work of Kusmaya[2014] shows similar trends for the four investigated processes, and similar power consumption was found for the four processes. The figures obtained in the present work are lower by about $5 \%$, and this difference can be explained by the discrepancies in the compressor and turbine efficiencies. However, as discussed by Wood et al.[2007], turbo-expander systems, despite their lower efficiencies, may be preferable over mixture-based ones as they are less sensible to motion and changes in the feed composition.

Scope. Future work within this topic will include performance comparisons for a higher number offshore liquefaction processes, such as the expansion-based processes with $\mathrm{CO}_{2}$-precooling, or with dual cycles with nitrogen and methane. All the investigated cycles should then be optimized with respect to the power consumption, required space and capital costs, in order to propose solutions that are technically and economically acceptable. An economic analysis coupled with a multi-objective optimisation routine may be a next step, as it would show clearly the trade-offs between (i) the additional costs of the liquefaction cycle against the gains in sales export, (ii) the overall performance and power consumption against the weight and footprint of the facility. Finally, caution should be exercised when extending or extrapolating these results - additional simulations may to assess whether the same trends are found for other petroleum properties, such as for heavy oil, and to optimize the resulting system if needed.

\section{Conclusion}

This paper deals with the integration of gas liquefaction processes on floating, production, storage and offloading facilities. The aim was to analyse these hybrid systems for several petroleum compositions and process layouts. Rigorous models were developed based on extensive data from literature surveys and industrial plants to predict accurately the system performance and synergies. The energy integration and exergy analysis methods were applied to identify the most inefficient processes and promising improvements.

The operating conditions of each process unit and the feed properties have a direct influence on the system performance. However, similar trends are found in all cases. The $\mathrm{CO}_{2}$ and gas compression processes are the major power consumers and account for a large share of the total exergy destruction. The exergy of the streams exiting the offshore plant exceeds $94 \%$ of the exergy of the inflowing ones, which illustrates the large amount of exergy transiting through the platform without being converted and just separated. 
Two liquefaction processes suitable for offshore implementation were assessed. The dual-mixed refrigerant process is more efficient than the turbo-expander one, but is the most sensitive to motion and variability in the feed composition. These processes highly influence the overall layout of the processing plant because of the stringent limits on the $\mathrm{CO}_{2}$ and $\mathrm{H}_{2} \mathrm{O}$ contents, which results in a more complex treatment process and greater fuel consumption. The selection of the acid gas treatment unit has a significant impact on the overall system integration: it influences the heating demand at moderate temperatures of $120^{\circ} \mathrm{C}$ and may impede opportunities for energy recovery.

Compared to a conventional platform where gas is directly injected into the reservoir, the total power consumption increases by up to $50 \%$ and the exergy destruction within the processing plant doubles when a liquefaction system is installed. With regards to these findings, and considering the costs of installing a LNG plant, it is essential to conduct a careful analysis of the trade-off between the capital costs and operating revenues for such options.

\section{Acknowledgements}

The present work was supported by the National Agency of Petroleum, Natural Gas and Biofuels (ANP) and BG E\&P Brasil Ltda, through Investment in Research, Development and Innovation Clause, contained in contracts for Exploration, Development and Production of Oil and Natural Gas. The authors acknowledge the financial support from the Fundação de Amparo à Pesquisa do Estado de São Paulo (São Paulo research foundation, FAPESP) and from the Conselho Nacional de Desenvolvimento Científico e Tecnológico (Brazilian National Council for Scientific and Technological Development, CNPq), through the grant 306033/2012-7.

\section{References}

Aspen Technology, 1999. Aspen Plus - Modelling Petroleum Processes. Aspen Technology, Burlington, USA.

Barclay, M., Denton, N., 2005. Selecting offshore LNG processes. LNG journal 10, 34-6.

Bothamley, M., 2004. Offshore Processing Options for Oil Platforms, in: Proceedings of the SPE Annual Technical Conference and Exhibition, Society of Petroleum Engineers, Houston, USA. pp. 1-17 (Paper SPE 90325).

Bunnag, M., Amarutanon, N., Nitayaphan, S., Aimcharoenchaiyakul, M., et al., 2011. Flng development: Strategic approaches to new growth challenges, in: International Petroleum Technology Conference, International Petroleum Technology Conference. pp. $1-15$.

Cao, W.s., Lu, X.s., Lin, W.s., Gu, A.z., 2006. Parameter comparison of two small-scale natural gas liquefaction processes in skid-mounted packages. Applied Thermal Engineering 26, 898-904.

Chang, H.M., 2015. A thermodynamic review of cryogenic refrigeration cycles for liquefaction of natural gas. Cryogenics 72 , $127-47$.

Finn, A., 2002. Effective lng production offshore, in: 81st Annual GPA Convention, pp. 1-18.

Finn, A.J., 2009. Floating lng plants-scale-up of familiar technology, in: GPA 88th Annual Convention, pp. 1-22. 
Gassner, M., Baciocchi, R., Maréchal, F., Mazzotti, M., 2009. Integrated design of a gas separation system for the upgrade of crude sng with membranes. Chemical Engineering and Processing: Process Intensification 48, $1391-404$.

International, S.U., 2009. Prelude Floating LNG Project. Technical Report. Shell Development (Australia) Proprietary Limited.

Kayat, Z., Schott, M., Doong, S., Subris, R., et al., 2012. Pretreatment of acid gas in feed for petronas floating lng facility, in: 25th World Gas Conference, Kuala Lumpur, Malaysia. pp. 1-11.

Kemp, I., 2006. Pinch Analysis and Process Integration - A User Guide on Process Integration for the Efficient Use of Energy. Elsevier Ltd.. second edition.

Kusmaya, M., 2014. Liquefaction process evaluation for floating LNG. Technical Report. SINTEF, NTNU. Trondheim, Norway. McCarrick, M.T., Kenneth, M., 2012. LM2500 to LM2500+DLE Gas Turbine Combined Cycle Plant Repowering. GE Energy. Mokhatab, S., Poe, W.A., 2012. Handbook of natural gas transmission and processing. Gulf Professional Publishing. Moran, M.J., 1989. Availability analysis: a guide to efficient energy use. ASME Press, New York, USA. 2nd edition.

Nezamian, A., Morgan, P., et al., 2014. Concept evaluation of concrete floating liquefied natural gas (flng), in: Offshore Technology Conference-Asia, Offshore Technology Conference. pp. 1-15.

Nguyen, T.V., Fülöp, T., Breuhaus, P., Elmegaard, B., 2014a. Life performance of oil and gas offshore platforms -site-scale integration and exergy-based assessment. Energy 73, 282-301.

Nguyen, T.V., Jacyno, T., Breuhaus, P., Voldsund, M., Elmegaard, B., 2014b. Thermodynamic analysis of an upstream petroleum plant operated on a mature field. Energy 68, 454-69.

Nguyen, T.V., Pierobon, L., Elmegaard, B., Haglind, F., Breuhaus, P., Voldsund, M., 2013. Exergetic assessment of energy systems on North Sea oil and gas platforms. Energy 62, 23-36.

Nguyen, T.V., Tock, L., Maréchal, F., Elmegaard, B., 2014c. Oil and gas platforms with steam bottoming cycles: Retrofit integration and thermo-environomic evaluation. Applied Energy 131, 222-37.

Oliveira Jr., S.D., Van Hombeeck, M., 1997. Exergy Analysis of Petroleum Separation Processes in Offshore Platforms. Energy Conversion and Management 38, 1577-84.

Peng, D.Y., Robinson, D.B., 1976. A New Two-Constant Equation of State. Industrial \& Engineering Chemistry Fundamentals $15,59-64$.

Pettersen, T., Lien, K.M., 1994. A new robust design model for gas separating membrane modules, based on analogy with counter-current heat exchangers. Computers \& chemical engineering 18, 427-39.

Redlich, O., Kwong, J., 1949. ON THE THERMODYNAMICS OF SOLUTIONS. V An Equation of State. Fugacities of Gaseous Solutions. Chemical Reviews 44, 233-44.

Remeljej, C., Hoadley, A., 2006. An exergy analysis of small-scale liquefied natural gas (lng) liquefaction processes. Energy 31, 2005-19.

Sánchez, Y., de Oliveira Jr., S., 2015. Exergy analysis of petroleum offshore platform process plant with $\mathrm{CO}_{2}$ capture. Energy $88,46-56$.

Sánchez, Y.A.C., de Oliveira Júnior, S., da Silva, J.A.M., Nguyen, T.V., 2015. Energy and Exergy Performance of three FPSO Operational Modes, in: Proceedings of the 23rd ABCM International Congress of Mechanical Engineering, pp. 1-8.

Shane, T., et al., 2015. Gas pretreatment considerations for floating lng, in: OTC Brasil, Offshore Technology Conference, Rio de Janeiro, Brazil. pp. 1-15.

Soave, G., 1972. Equilibrium constants from a modified Redlich-Kwong equation of state. Chemical Engineering Science 27, $1197-203$.

Svalheim, S.M., King, D.C., 2003. Life of Field Energy Performance, in: Proceedings of the SPE Offshore Europe Conference, Society of Petroleum Engineers, Aberdeen, United Kingdom. pp. 1-10 (Paper SPE 83993).

Szargut, J., 1989. Chemical exergies of the elements. Applied Energy 32, 269-86.

Tock, L., Maréchal, F., 2013. Process engineering method for systematically comparing $\mathrm{CO}_{2}$ capture options. Computer Aided 
Chemical Engineering 32, 367-72.

Voldsund, M., Ertesvåg, I.S., He, W., Kjelstrup, S., 2013. Exergy Analysis of the Oil and Gas Processing a Real Production Day on a North Sea Oil Platform. Energy 55, 716-27.

Voldsund, M., Nguyen, T.V., Elmegaard, B., Ertesvåg, I., Røsjorde, A., Jøssang, K., Kjelstrup, S., 2014. Exergy destruction and losses on four North Sea offshore platforms: A comparative study of the oil and gas processing plants. Energy 74 , 45-58.

Wood, D., Mokhatab, S., Economides, M.J., et al., 2007. Offshore natural gas liquefaction process and development issues. SPE Projects, Facilities \& Construction 2, 1-7. 

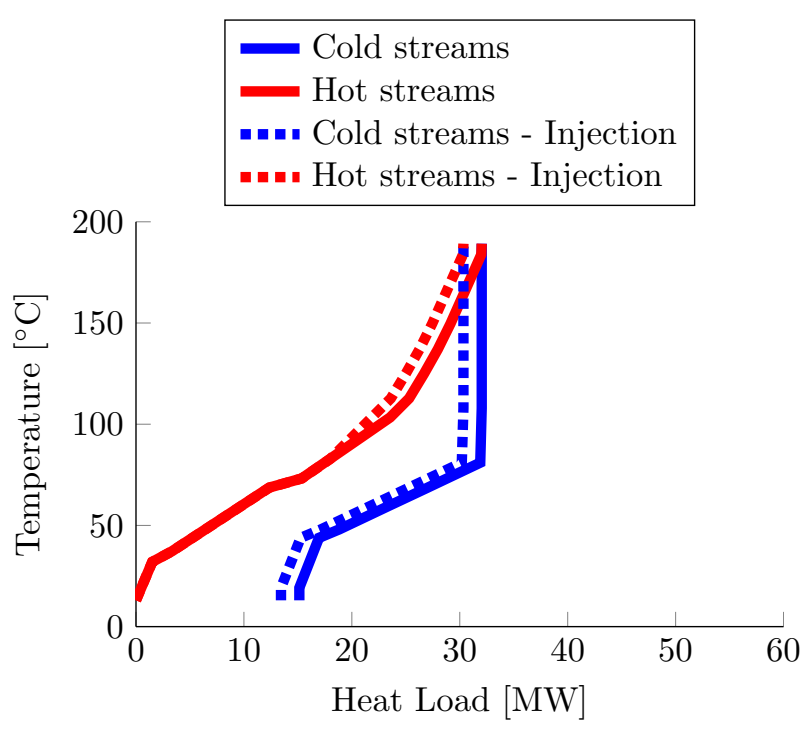

(a) Petroleum with low $\mathrm{CO}_{2}$-content
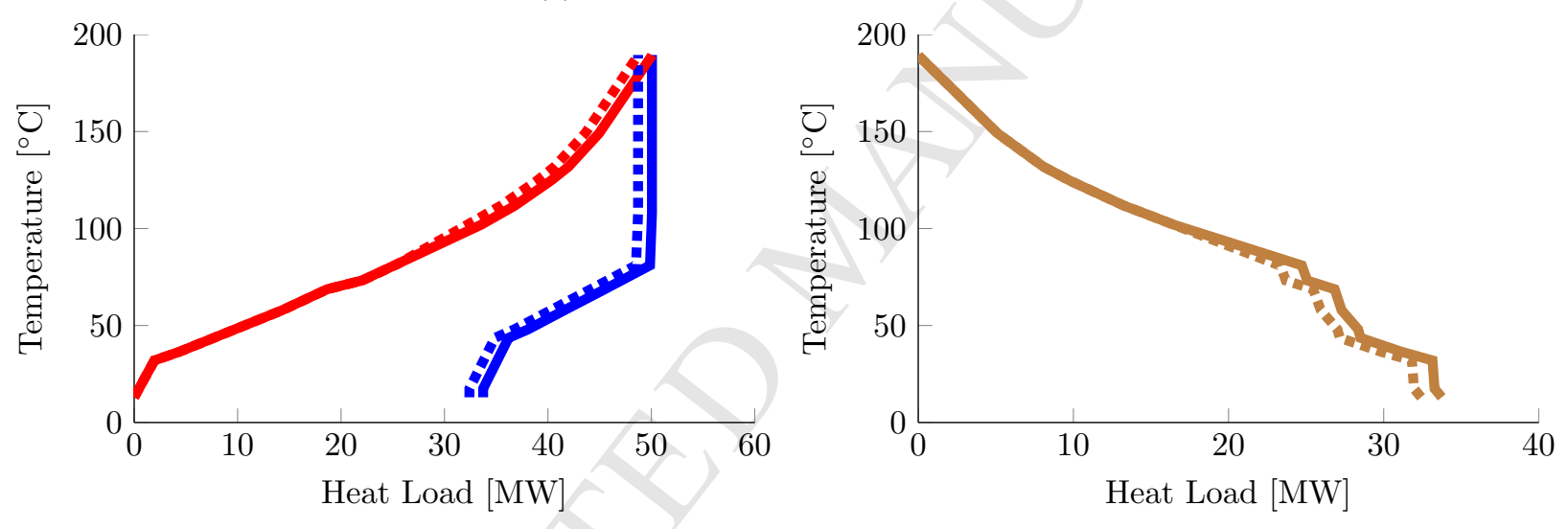

(b) Petroleum with high $\mathrm{CO}_{2}$-content
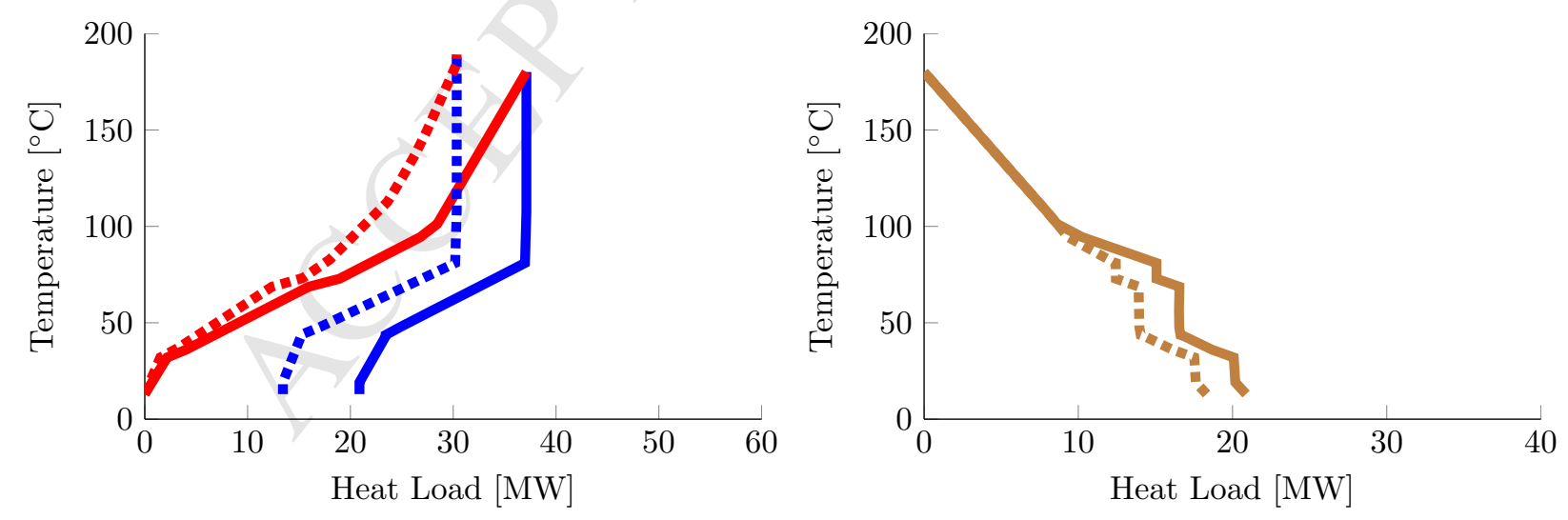

(c) Petroleum without $\mathrm{CO}_{2}$

Figure 4: Temperature-heat profiles of the platform - cooling and heating demands (left) and grand composite curve (right) for the export and injection modes 


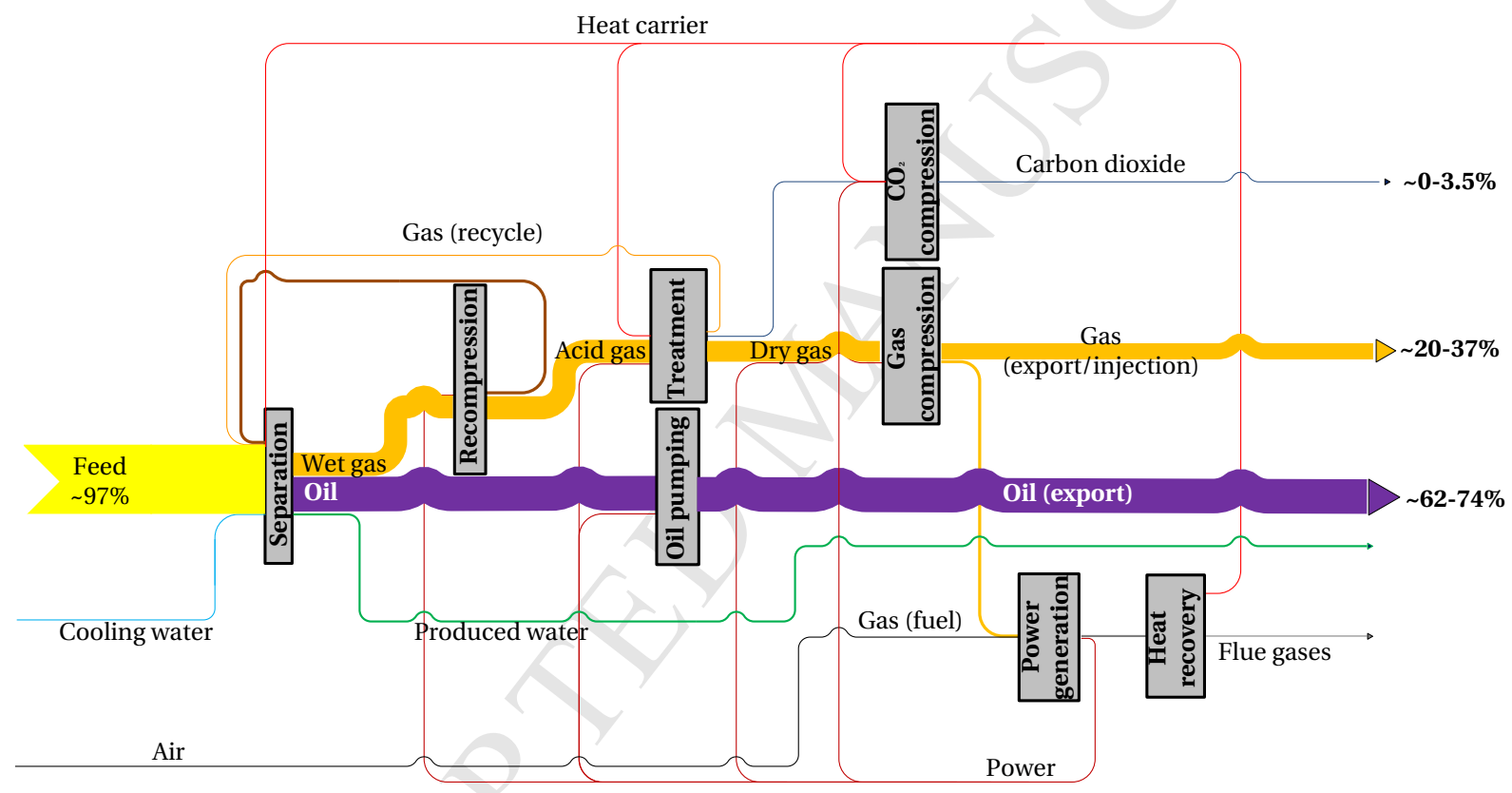

Figure 5: Sankey diagram of the offshore system 


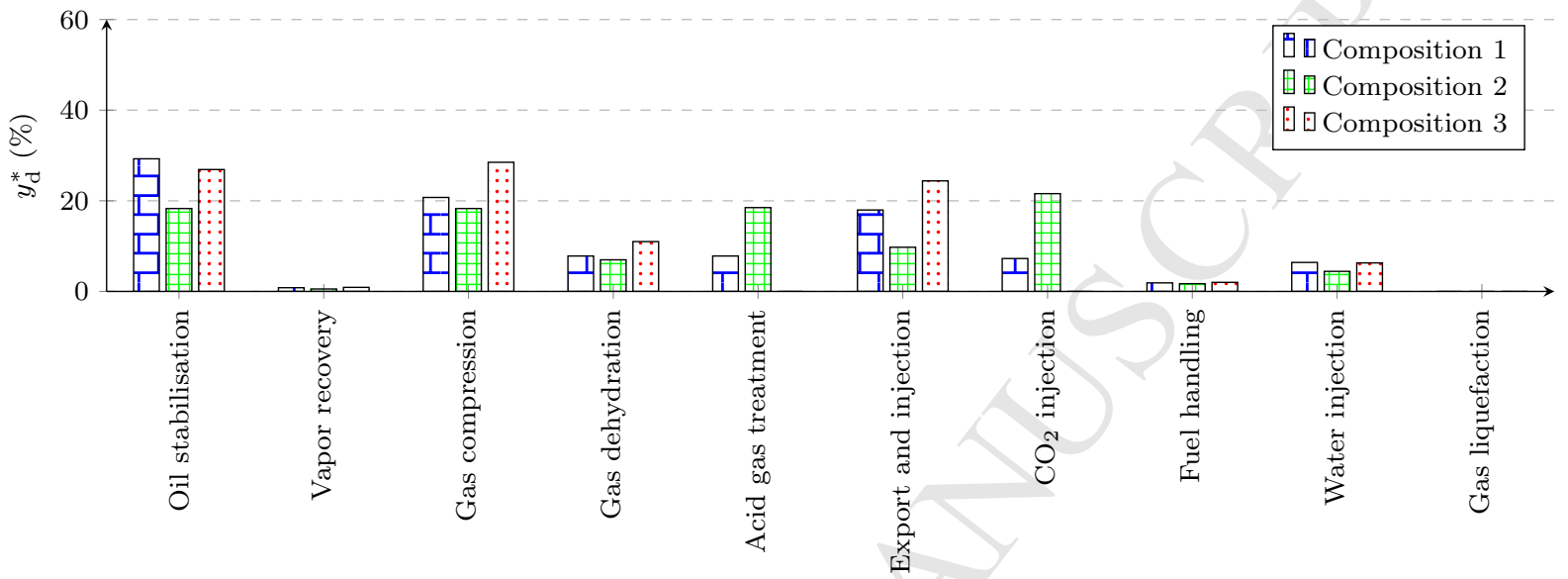

(a) Exergy destruction share for the processing plant, sorted by process

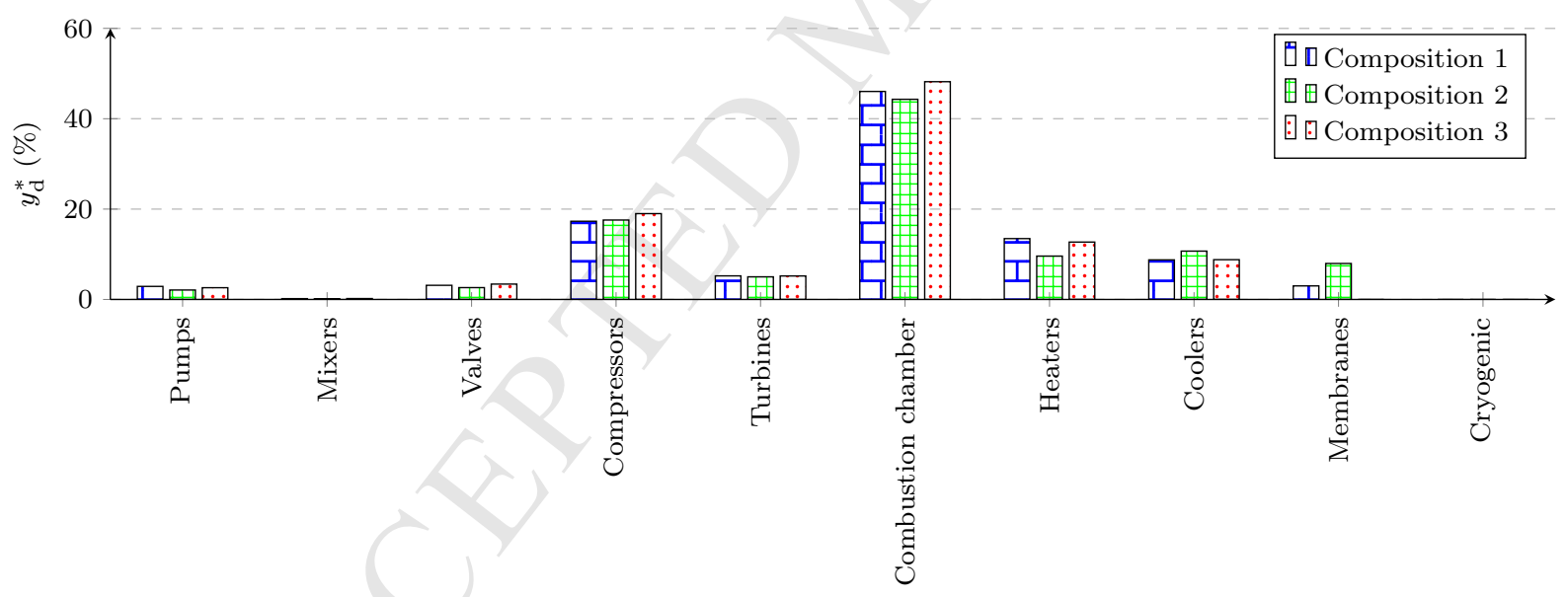

(b) Exergy destruction share for the complete platform, sorted by component type

Figure 6: Exergy destruction share for petroleum feeds with low, high and no contents of carbon dioxide. 
Cold streams Hot streams

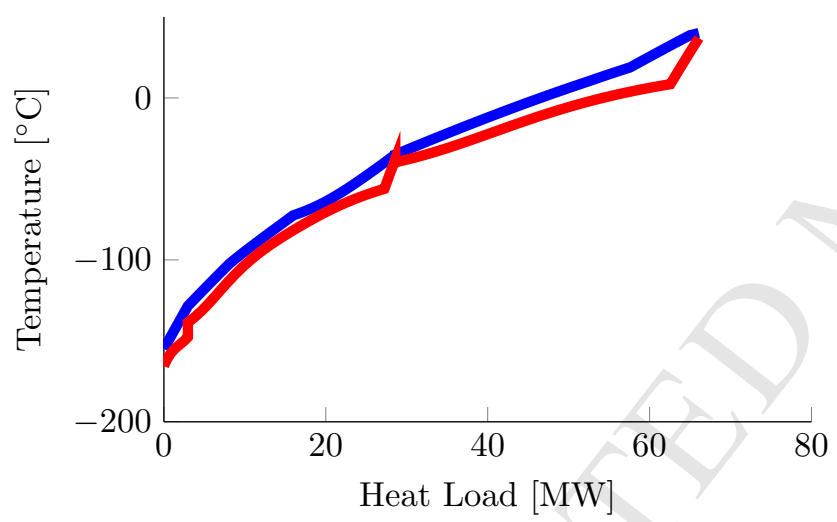

Cold streams

Hot streams

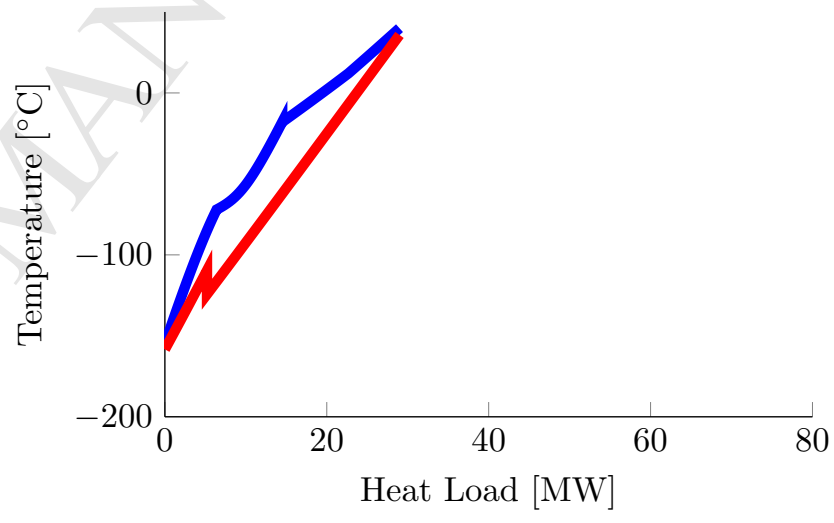

Figure 7: Temperature-heat profiles of the dual mixed-refrigerant (DMR) or dual reverse Brayton (DRB) processes, for the low $\mathrm{CO}_{2}$-content case 

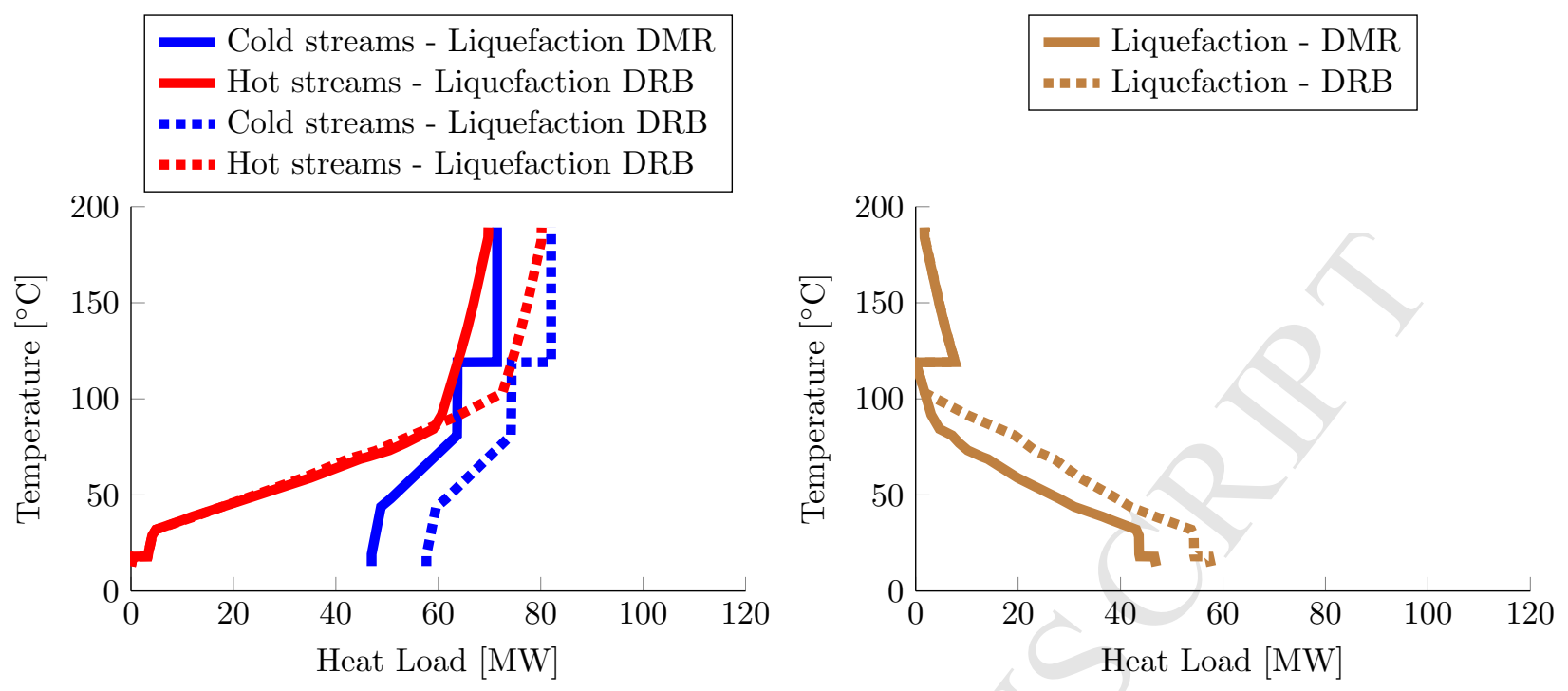

(a) Petroleum with low $\mathrm{CO}_{2}$-content
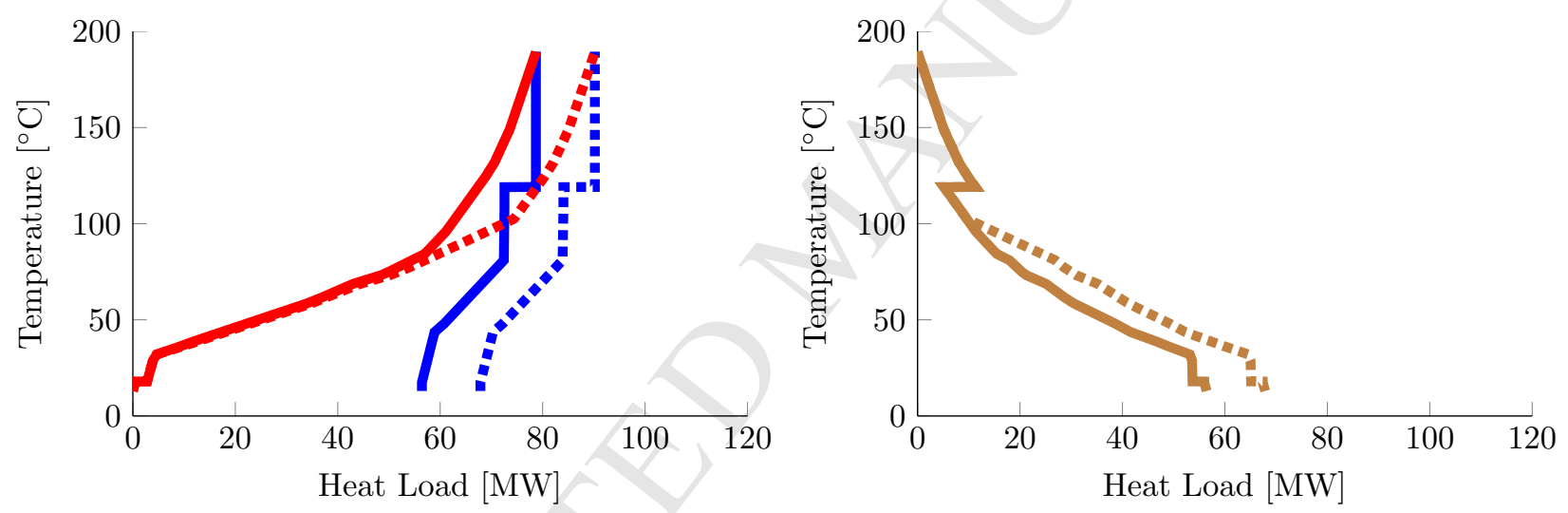

(b) Petroleum with high $\mathrm{CO}_{2}$-content
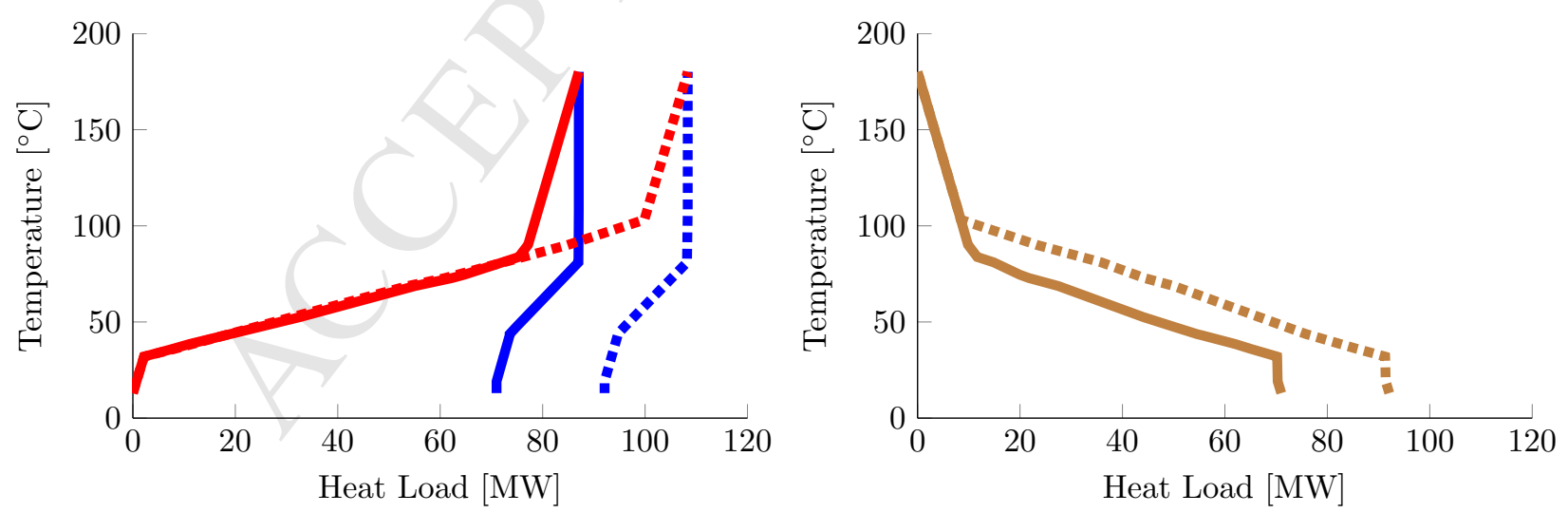

(c) Petroleum without $\mathrm{CO}_{2}$-content

Figure 8: Temperature-heat profiles of the platform - cooling and heating demands (left) and grand composite curve (right) for the liquefaction modes 


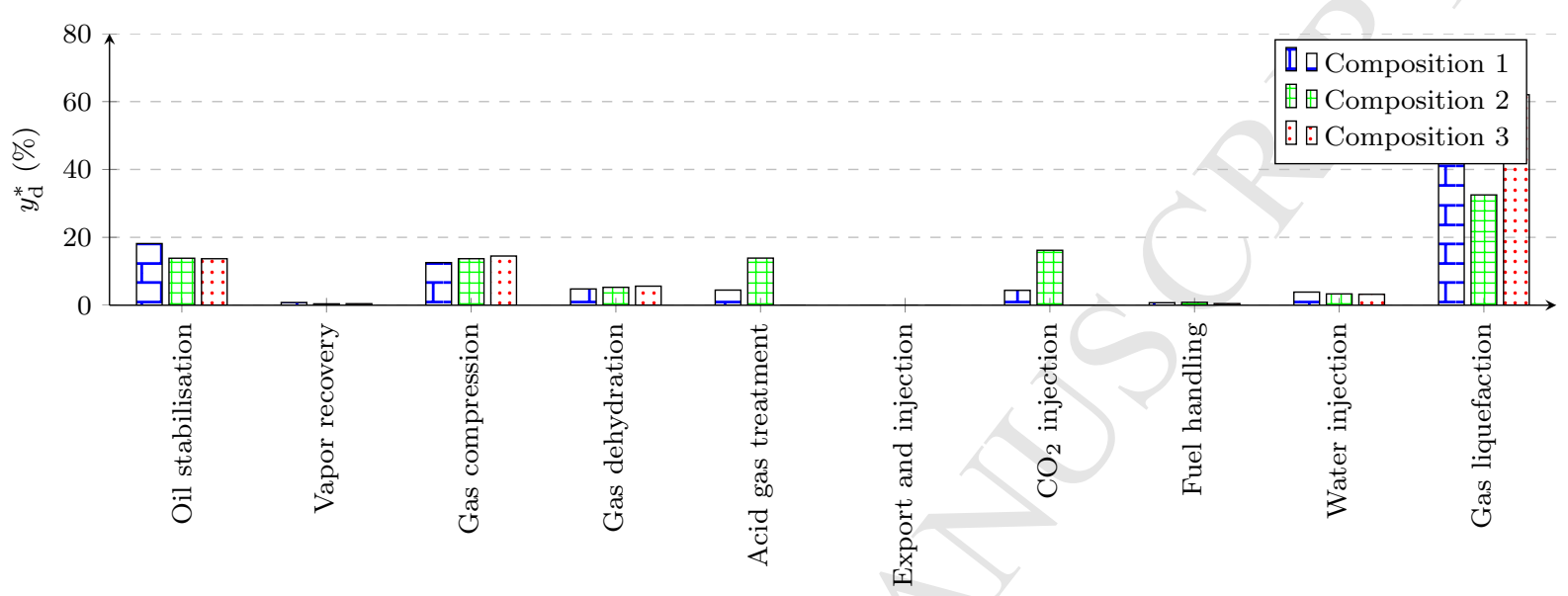

(a) Exergy destruction share for the processing plant, sorted by process

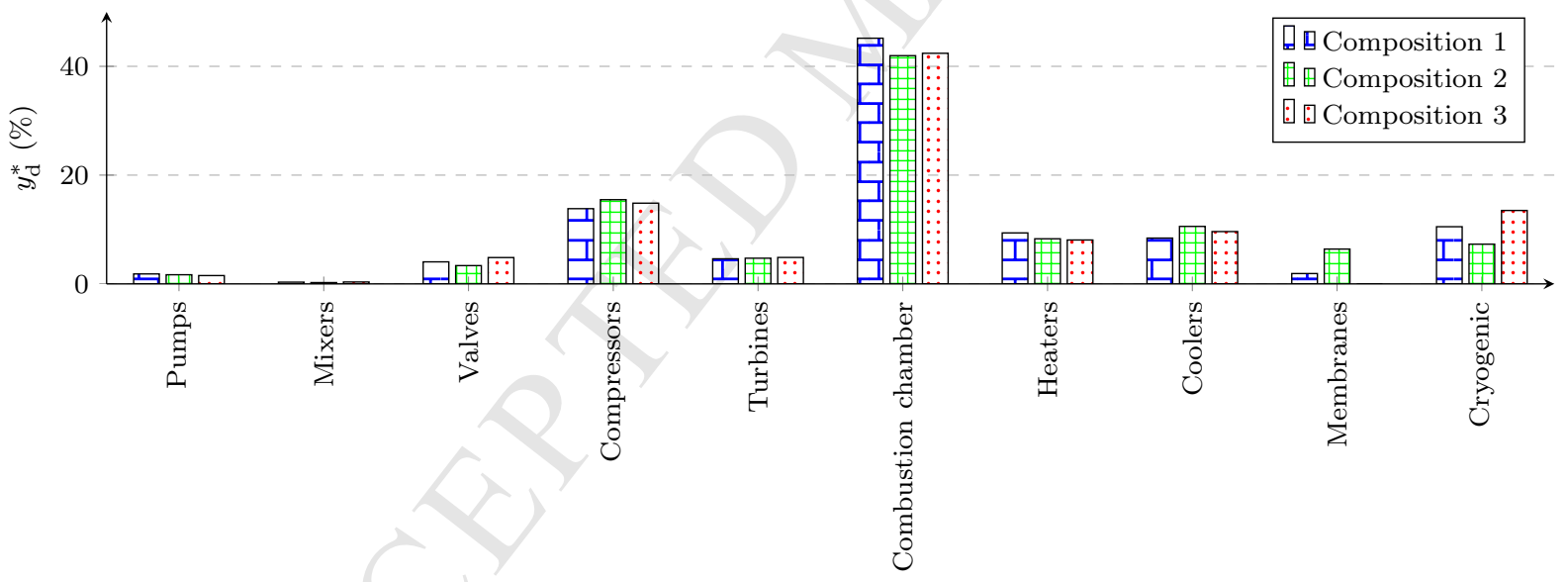

(b) Exergy destruction share for the complete platform, sorted by component type

Figure 9: Exergy destruction share with low, high and no contents of carbon dioxide, when integrating a dual mixed-refrigerant process. 


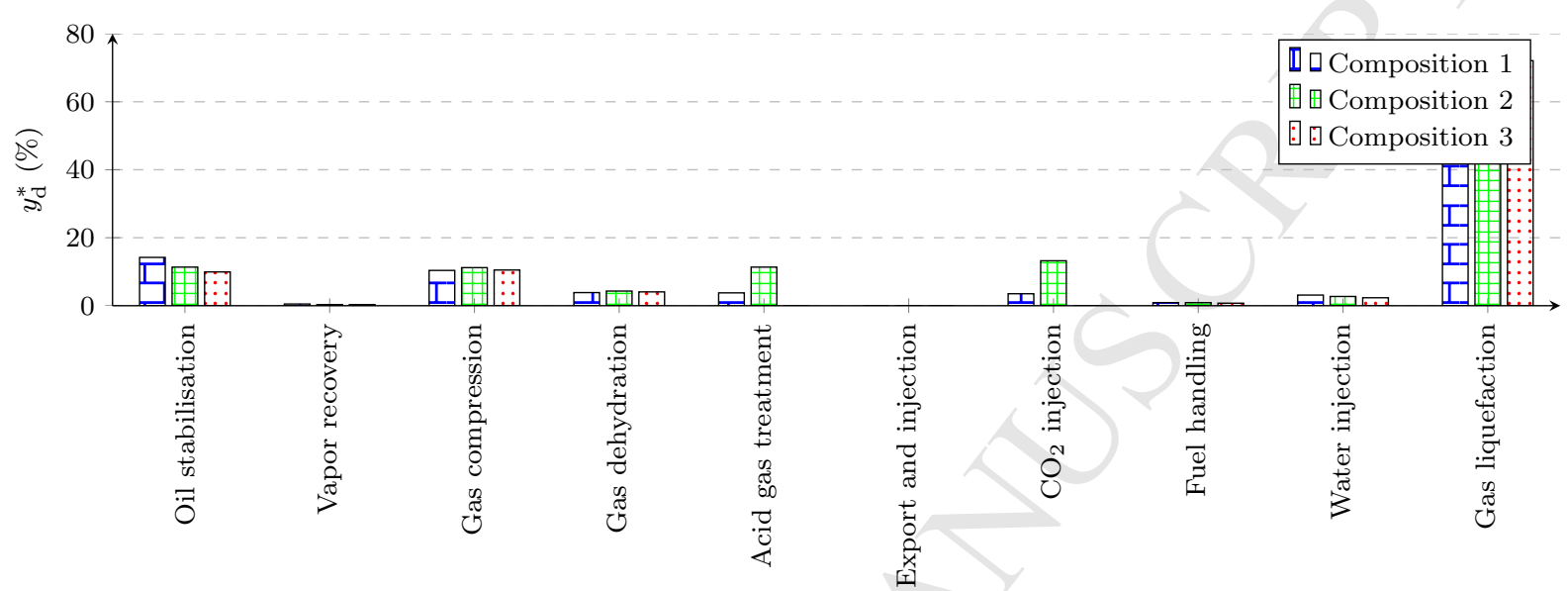

(a) Exergy destruction share for the processing plant, sorted by process

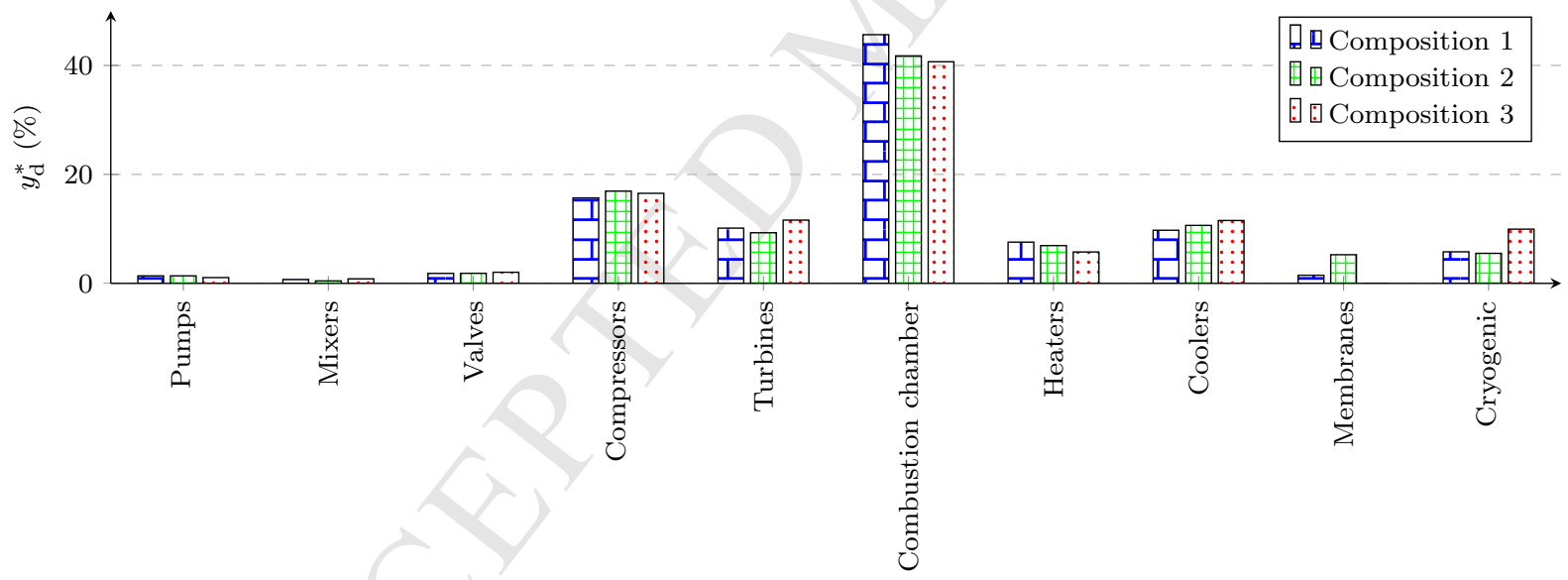

(b) Exergy destruction share for the complete platform, sorted by component type

Figure 10: Exergy destruction share with low, high and no contents of carbon dioxide, when integrating a dual-reverse Brayton cycle. 
Highlights: System evaluation of offshore platforms with gas liquefaction processes

- Energy and exergy performance of floating production storage and offloading platforms

- Integration of gas liquefaction processes

- System analysis of the hybrid processing plant

- Significant changes of the plant layout and efficiency 